\title{
High pressure paint gun injury of the index finger: a case report
}

\author{
Memet Yazar ${ }^{1}$, Zeliha Gül${ }^{1}$, Ali Can Günenç${ }^{1}$, Sevgi Kurt Yazar², Erol Kozanoğlu \\ ${ }^{1}$ Plastic, Reconstructive and Aesthetic Surgery Clinic, Sisli Etfal Training and Research Hospital, 34371 Istanbul, Turkey. \\ ${ }^{2}$ Plastic, Reconstructive and Aesthetic Surgery Clinic, Istanbul Training and Research Hospital, 34098 Istanbul, Turkey. \\ ${ }^{3}$ Plastic, Reconstructive and Aesthetic Surgery Clinic, Istanbul University, Istanbul Medicine Faculty, 34093 Istanbul, Turkey.
}

Address for correspondence: Dr. Memet Yazar, Plastic, Reconstructive and Aesthetic Surgery Clinic, Sisli Etfal Training and Research Hospital, 34371 Istanbul, Turkey. E-mail: memetyazar@gmail.com

\begin{abstract}
Injuries to the hand secondary to high pressure paint guns are considered to be true hand emergencies. These rare injuries may have serious outcomes, and a critical step in their management is extensive debridement performed within the first six hours following injury. For this reason, their diagnosis should not be delayed, and the hand surgeon should be informed immediately to initiate appropriate treatment. In this report, the authors describe a patient who was injured with a chemical paint gun, and whose injury was not diagnosed in the emergency department. The patient subsequently developed tenosynovitis. His treatment is reported herein.
\end{abstract}

Key words:

Finger injury, high pressure injury, trauma

\section{INTRODUCTION}

Hand infections are emergencies of hand surgery that require prompt treatment. The hand is a unique part of the body as it possesses fine compartments with vital structures. Hand infections can accumulate within these compartments through the tendon sheaths and lymphatics, elevating compartmental pressure and progressing to ischemia and necrosis. If the infection spreads to surrounding vital structures, serious functional deficits and even death may occur. ${ }^{[-3]}$

Generally, hand infections can develop following minor trauma such as foreign body penetration and lacerations. In addition, human or animal bites, surgery and intravenous lines may also be associated with infections of the hand. ${ }^{[4,5]}$ Although injuries due to high pressure injection devices mostly used in manufacturing systems are very rare, they necessitate acute treatment to prevent potentially serious complications. ${ }^{|6|}$

\begin{tabular}{|l|l|}
\hline \multicolumn{2}{|c|}{ Access this article online } \\
\hline Quick Response Code: & Website: \\
\hline & www.parjournal.net \\
\hline & \\
\hline
\end{tabular}

In this study, the authors describe a patient who was injured with a chemical paint gun, and whose injury was not initially diagnosed in the emergency department. The patient developed pyogenic tenosynovitis, and his treatment is reported here.

\section{CASE REPORT}

A 34-year-old man was referred to our emergency department with the complaints of pain and swelling at the distal phalangeal level of his left index finger. The symptoms began after he was injured with a paint injection gun in a professional setting. The emergency department physicians evaluated the patient and discharged him with prescriptions for oral antibiotics (cefazolin) and analgesics after administration of tetanus prophylaxis. Although

This is an open access article distributed under the terms of the Creative Commons Attribution-NonCommercial-ShareAlike 3.0 License, which allows others to remix, tweak, and build upon the work non-commercially, as long as the author is credited and the new creations are licensed under the identical terms.

For reprints contact: reprints@medknow.com

How to cite this article: Yazar M, Gül Z, Günenç AC, Yazar SK, Kozanoglu E. High pressure paint gun injury of the index finger: a case report. Plast Aesthet Res 2015;2:350-2.

Received: 19-04-2015; Accepted: 06-09-2015 
no osseous pathology was detected on his initial radiograph, the radiopaque appearance of the paint could be clearly recognized [Figure $1 \mathrm{a}$ and b], demonstrating the high viscosity of the injected material. When the radiograph was evaluated carefully, the paint was noted to have spread proximally through the flexor tendon sheath [Figure 1a and b].

Despite conservative treatment, the pain did not subside, and venous congestion of the finger increased in Figure 2. The patient returned to the emergency department on the following day at which time he was referred to our department with the diagnosis of an infection of the distal phalanx. His examination at that time was remarkable for significant edema of the digit, with an elevated white blood cell count. The differential diagnosis included felon and pyogenic tenosynovitis, and the patient was admitted immediately and taken to the operating room. Mid-lateral incisions were made with findings remarkable for an abscess with a foul odor and tissue necrosis. The pulp was irrigated, dressed and splinted. Cefazolin and gentamicin were ordered for microbial coverage, and dextran 40 and enoxaparin sodium were ordered for circulatory support.

The following day, there were still overt signs of infection, and the patient underwent re-operation. Palmar Z-incisions were made for exposure of the flexor tendon sheaths, and repeat debridement was performed. The paint was found at the level of the proximal phalanx. Both neurodigital bundles and the flexor digitorumprofundus tendon were noted to have sustained damage by lysis secondary to the infection [Figure 3a]. The soft tissue and bone were debrided aggressively [Figure 3b], and the deep tissue was sampled for microbiological studies. On the 4th day of hospitalization, cultures revealed mixed Gram-negative bacteria with the growth of Citrobacter freundii, Morganella morgani and Proteus vulgaris. The Department of Infectious Diseases was consulted, and ciprofloxacin and metronidazole were administered per their recommendation. During his stay, the patient was treated with daily povidone-iodine finger baths, the wound dressing was changed daily, and the extremity was elevated continuously. The white blood cell count returned to a normal range by the 10th postoperative day, and the inflammation signs such as swelling and edema subsided. The pulp defect was then reconstructed with a cross-finger flap [Figure 4].

The fingers were attached for 10 days at which time the pedicle was divided. The patient was transferred to physical therapy after recovering from surgery, and eventually returned to his occupation 2 months after the first session of physical therapy. He was evaluated 12 months postinjury with Semmes-Weinstein monofilaments and two-point discrimination tests for sensation. According to these tests, the patient had normal sensation (Semmes-Weinstein: value 2.83, corresponding to green color). Tactile sensation was considered to be good to moderate with two-point discrimination at $6.5 \mathrm{~mm}$. The patient had mild contractures at the proximal

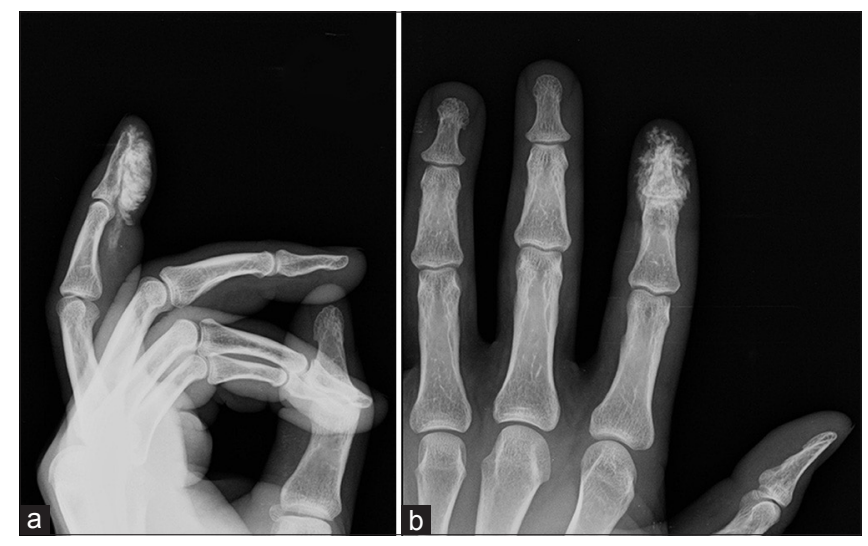

Figure 1: (a) Lateral radiographic view; (b) anteroposterior radiographic view of the patient, the radiopaque appearance of the paint could be recognized clearly

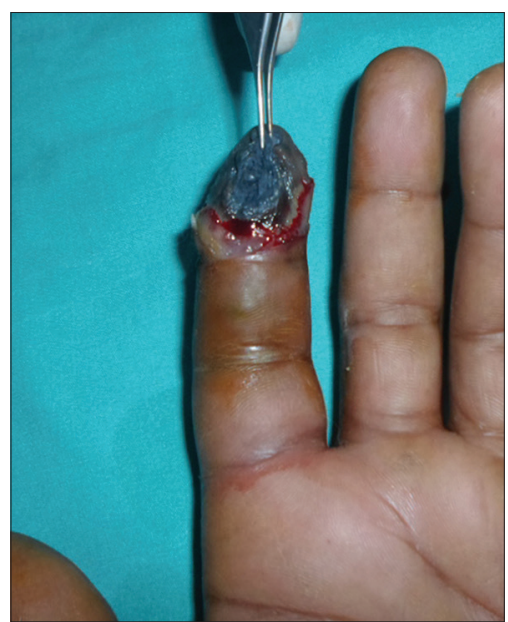

Figure 2: Necrosis of the pulp at the time of referral to the plastic surgery clinic

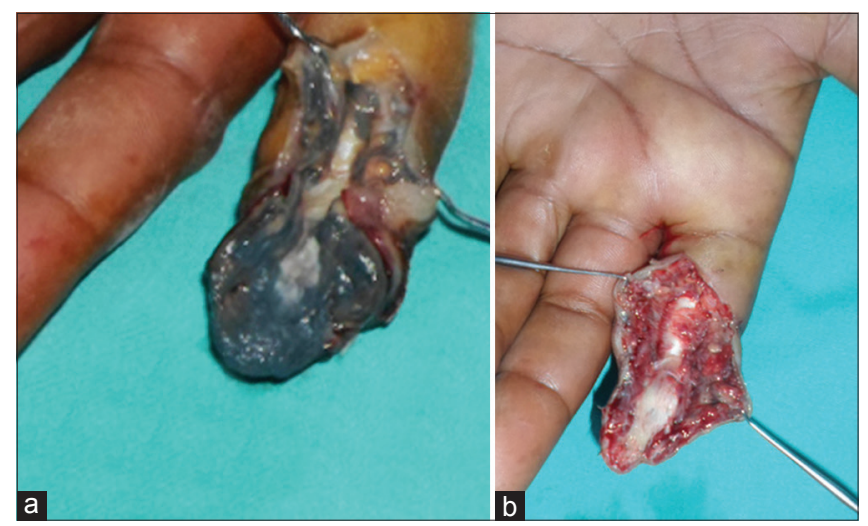

Figure 3: (a) Preoperative view of the paint along the neurovascular bundles and flexor tendon sheats; (b) the view after debridement

interphalangeal (PIP) and distal interphalangeal (DIP) joints $\left(10^{\circ}-15^{\circ}\right.$ at the PIP and $10^{\circ}$ at the DIP).

\section{DISCUSSION}

High pressure paint gun injuries of the hand and fingers are very rare, but can progress to amputation. The diagnosis is usually delayed secondary to the benign initial appearance combined with a lack of appropriate clinical knowledge among physicians. Surgical intervention including aggressive 


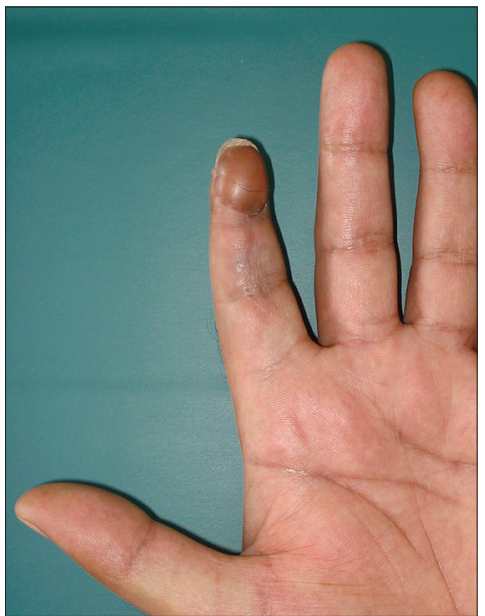

Figure 4: Final postoperative view of the patient after reconstruction with a cross-finger flap

debridement and decompression must be undertaken in the first $6 \mathrm{~h}$ to decrease the risk of amputation. Despite aggressive therapy, the risk of amputation ranges from $22 \%$ to $48 \%{ }^{\left[{ }^{[6]}\right.}$ Local necrosis appearing after the first $6 \mathrm{~h}$ postinjury may be associated with infection and advancing necrosis which spreads proximally. ${ }^{[7-9]}$

In their study, Hogan and Ruland defined the epidemiology of high pressure paint gun injuries. ${ }^{[10]}$ The majority of the patients were men with a mean age of thirty-five years. The index finger of the nondominant hand was the most frequent injured digit. Tissue damage may be either chemical or mechanical in nature. In general, the injected material creates a small open wound at the entrance point, with the material passing through the tissue and neurovascular structures until it faces resistance. This movement causes traumatic dissection with pressure secondary to the injected fluid potentially causing compartment syndrome. The process advances further with an increase in volume secondary to edema and the inflammation. Because the injected material itself may cause chemical damage, the clinical condition can rapidly deteriorate. All of these factors impair circulation while destroying tissue, increasing the susceptibility to infection. For this reason, a regimen of broad spectrum antibiotics is recommended by most authors. In Hogan and Ruland's study, the microbiological culture was positive with mixed bacteria in forty-two percent of the patients. ${ }^{[10]}$ Infection can develop even in patients who receive antibiotic therapy. However, their study did not show a statistically significant difference in amputation rates between culture positive and culture negative patients. ${ }^{[10]}$

If the patient has been injected with a material other than water or air, debridement must be undertaken within the first $6 \mathrm{~h}$. Local-regional or general anesthesia should be administered because the proximal extent of the injury cannot be known with certainty preoperatively. Digital nerve blocks are not recommended given the risk of increased compression at the fingers. The tourniquet should be applied cautiously to avoid proximal migration of the injected material. Reconstruction and skin repair can be delayed until a secondary debridement 24-48 h later. Flaps may be utilized in reconstruction following regression of the infection, depending on the condition of the open wound. Although there is controversy regarding their use, steroids may be administered to decrease inflammation. Despite treating 15 patients with steroids, Hogan and Rutland noted that 8 of these patients still required amputation. ${ }^{[10]}$

The most significant prognostic factor in high pressure gun injuries is early diagnosis with prompt notification of a hand surgeon. The rate of amputation has been shown to be lower in patients who received debridement of necrotic tissues within the first six hours following injury (58\% vs. 88\%)..$^{[9]}$ On the other hand, the properties of the injected material are also very important, as injuries with organic solvents (thinner, gasoline, etc.) have a higher risk of amputation than other materials. ${ }^{[10]}$

In conclusion, high pressure gun injuries are rare but constitute a true surgical emergency of the hand. The emergency department staff must be educated about such injuries to prevent a delay in diagnosis. As noted above, the most important prognostic factor is aggressive debridement undertaken within the first six hours following injury. For this reason, the hand surgeon must be consulted, broad spectrum antibiotics must be administered promptly, and tissues must be debrided as early as possible.

\section{Financial support and sponsorship} Nil.

\section{Conflicts of interest}

There are no conflicts of interest.

\section{REFERENCES}

I. Best RR. An Anatomical and clinical study of infections of the hand. Ann Surg 1929;89:359-78.

2. Ki V, Rotstein $\mathrm{C}$. Bacterial skin and soft tissue infections in adults: a review of their epidemiology, pathogenesis, diagnosis, treatment and site of care. Can J Infect Dis Med Microbiol 2007; 19:173-84.

3. Rigopoulos N, Dailiana ZH, Varitimidis S, Malizos KN. Closed-space hand infections: diagnostic and treatment considerations. Orthoped Rev 20 I 2;4:e 19.

4. Clark DC. Common acute hand infections. Am Fam Physician 2003;68:2 167-76.

5. Bach HG, Steffin B, Chhadia AM, Kovachevich R, Gonzalez MH. Community-associated methicillin-resistant Staphylococcus aureus hand infections in an urban setting. J Hand Surg Am 2007;32:380-3.

6. Bekler H, Gokce A, Beyzadeoglu T, Parmaksizoglu F. The surgical treatment and outcomes of high-pressure injection injuries of the hand. J Hand Surg Eur Vol 2007;32:394-9.

7. Smith GD. High pressure injection injuries. Trauma 2005;7:95-103.

8. Öktem F, Öçgüder A, Altuntaș N, Bozkurt M, Tellioğlu AT. High pressure paint gun injection injury of the hand: a case report. J Plast Reconstr Aesthet Surg 2009;62:el57-9.

9. Amsdell SL, Hammert WC. High-Pressure Injection Injuries in the hand: current treatment concept. Plast Reconstr Surg 2013;132:e586-91.

10. Hogan CJ, Ruland RT. High-pressure injection injuries to the upper extremity: a review of the literature. J Orthop Trauma 2006;20:503-I I. 